\title{
PONTO DE LUZ: A CONFIGURAÇÃO DE IDENTIDADES ATRAVÉS DE UM PRODUTO MIDIÁTICO
}

\author{
POINT LIGHT: \\ THE CONFIGURATION A IDENTITIES THROUGH A MEDIA PRODUCT
}

\author{
PUNTO DE LUZ: \\ LA CONFIGURACIÓN DE IDENTIDADES A TRAVÉS DE UN PRODUCTO \\ DE LOS MEDIOS
}

Jozéli da Rosa Mônego

Mestre, Universidade Federal de Santa Maria

jozelirs@yahoo.com.br

Elizabeth Bastos Duarte

Doutora, da Universidade Federal de Santa Maria

bebethb@terra.com.br

\begin{abstract}
Resumo
O presente trabalho propõe-se a examinar as características gerais da religiosidade no Brasil contemporâneo. Contextualizando a forma de atuação midiática de igrejas, em particular as neopentecostais, analisa seu próspero crescimento, frente às características da sociedade atual. Com este objetivo, verifica as estratégias comunicativas e discursivas empregadas por instituições religiosas, no caso em estudo, a Igreja Universal do Reino de Deus (IURD) para interpelar seus fiéis. Suas estratégias passam pela compra de emissoras de televisão e exibição de programas nos quais há a construção de identidade da própria IURD, via seus prepostos, seus fiéis e aqueles fiéis em potencial que as mídias então convocam. O estudo centra-se no exame de um programa em particular, o Ponto de luz.
\end{abstract}

Palavras chaves: Religiosidade. Igreja Universal do Reino de Deus. Programas audiovisuais. Identidad. Estratégias de promoção religiosa.

\begin{abstract}
His work present proposes to examine the general characteristics of religiosity in contemporary Brazil. Contextualizing the role of media such as churches, in particular neopentecostais seeks to understand its prosperous growth, opposite to the characteristics of current society. With this objective, examines the media strategies employed by these religious institutions, in our case, the Universal Church of the Kingdom of God (IURD), to question its faithful, which involves the construction of identity itself IURD through its agents, its faithful and those who believe in potential, that the media call. Thus, examining in particular a television program, Point of light.
\end{abstract}

Esta obra está licenciada sob uma Licença Creative Commons 
Key words: Religiosity. Universal Church of Kingdom God. Audiovisual programs, Identities. Religion Promotion Estrategies.

\section{Resumen}

En este trabajo se propone examinar las características generales de la religiosidad en el Brasil contemporáneo. Contextualizando la forma de actividades de los medios de las iglesias, en particular el neo-pentecostales, analiza su próspero crecimiento, en comparación con las características de la sociedad actual. Para ello, comprueba las estrategias comunicativas y discursivas empleadas por las instituciones religiosas, en nuestro caso, la Iglesia Universal del Reino de Dios (IURD) a la pregunta a sus fieles. Sus estrategias incluyen la compra de emissoras de televisión y exibicion de programas, adonde hay la construcción de la propia identidad Iurdiana, via sus prepostos, sus agentes, sus creyentes y aquellos fieles potencial que los medios de comunicación luego convocan. El estudio se centra en el examen de un programa en particular, el Ponto de Luz.

Palabras clave: Religiosidad. Iglesia Universal del Reino de Dios. Programas audiovisuales. Identidades. Estrategias de promoción religiosas.

\section{INTRODUÇÃO}

O artigo é instigado pela constatação de que os programas religiosos, tão comuns em nossa rede de televisão brasileira, estão inseridos em um contexto muito peculiar, em que a religiosidade, no Brasil, cresce a cada dia, assim como o número de igrejas e templos religiosos. Contrariando teorias que tomavam a religião como campo social fadado ao extermínio, especialmente após a disseminação dos meios de comunicação e informação. Mas o que se tem notado, fora justamente o contrário, as instituições religiosas se apropriam de mecanismos de produção audiovisual e através deles tem um crescimento acelerado.

Tal crescimento é notado, tendo como referência a Igreja Universal do Reino de Deus (IURD), que se destaca e se visibiliza perante a sociedade, através das mídias, com inserções em rádios, televisões, revistas, internet, jornais, e outras mídias secundárias, como folheto e panfletos, causando muitas discussões a respeito da missão da Igreja, e a possível contradição desta missão pelas formas de atuar, tanto no âmbito do discurso quanto nas práticas que efetua junto a sociedade, especialmente com relação a arrecadação de doações dos fiéis, que ocorre de forma compulsória e sua interferência em outros campos sociais como na política e, especialmente, na mídia audiovisual.

É com base nesse cenário e tendo como pano de fundo as relações instituídas entre igreja e sociedade que se objetivou realizar um estudo entorno de um programa audiovisual, exibido ao público do Rio Grande do Sul, produzido por instâncias midiáticas diretamente 
ligadas à Igreja Universal do Reino de Deus (IURD). O Objetivo do trabalho é examinar as características gerais da religiosidade no Brasil contemporâneo; contextualizar a forma de atuação midiática das igrejas neopentecostais; compreender seu próspero crescimento, frente às características da sociedade atual; analisar as estratégias e mídias empregadas pela Igreja Universal do Reino de Deus (IURD) ao interpelar seus fiéis; verificar como se configura a identidade da IURD, de seus fiéis e daqueles fiéis em potencial, através de um programa de televisão, intitulado Ponto de Luz, com vistas a compreender que valores são convocados nessa interpelação dos públicos ao templo e a participar ativamente desta instituição religiosa.

Como já se referiu anteriormente, o objeto do trabalho é um programa religioso, intitulado Ponto de Luz; produzido por instâncias da Igreja Universal do Reino de Deus; exibido pela Rede Bandeirantes de Televisão, via canal aberto, de segunda a sexta-feira, das $13: 30 h$ às 15 horas.

O programa Ponto de Luz foi concebido tendo presente a idéia de que ele faz parte de um conjunto de estratégias midiáticas empregadas pela IURD com vistas à sua autopromoção, à sua legitimação junto ao social e, principalmente, tendo em vista à convocação do telespectador a comparecer ao templo religioso, onde ele poderá ter maior acesso a toda lógica que rege a instituição religiosa em estudo.

\section{SOBRE A IDENTIDADE E O TEXTO TELEVISUAL}

A construção de uma identidade favorece o processo de interpelação dos sujeitos receptores, que se sentem então participantes de uma comunidade, seja ela uma cultura latu senso ou uma comunidade de sentido, como a religiosa que se pretende analisar.

Identidade é uma construção social e um conjunto de traços individuais e grupais que unem sujeito pela semelhança e os distingue pela diferença. Ela é construída no interior de um processo discursivo que envolve estratégias de comunicação e manipulação.

É necessário lembrar que nenhum processo discursivo é inocente; há sempre intencionalidade de parte dos sujeitos da comunicação; há sempre manipulação.

Por outro lado, é preciso ter consciência de que a identidade não é uma essência, não é um fato ou um dado - seja da ordem da natureza ou da cultura; ela não é fixa, estável, coerente, unificada, permanente, tampouco homogênea, definitiva, acabada, idêntica, transcendental. Ela é uma construção, o efeito de um processo de produção discursiva, contraditório, fragmentado, inconsistente, inacabado, estando ligada a estruturas discursivas e narrativas, que se manifestam em textos. 
Vale salientar que os textos a que se refere o trabalho diz respeito a textos televisuais, que são produzidos a partir de uma lógica econômica mercantilista, eles são produtos, mercadorias. Eles são o resultado material do discurso, de um processo de significação, podendo ser expressos em diferentes linguagens: a plástica, cortes em cena, planos, justaposições de cenas em movimento, montagens e edição, além de elementos sonoros e visuais.

A IURD conhece todas as formas de interpelação e as utiliza sem pejo. Afinal as mídias são os meios mais rápidos de difusão de ideologias.

\subsection{Aspectos concernentes à Igreja Universal do Reino de Deus}

Antes de tratarmos do programa em si, sua estrutura e abordagens discursivas é necessário conhecer algumas características básicas da Igreja, pois esta compreensão facilita a análise do produto midiático.

A Igreja Universal do Reino de Deus pertence à corrente religiosa ligada ao neopentecostalismo, movimento este que tem suas origens no protestantismo de Martin Lutero.

Aqui, a IURD é compreendida como detentora de uma teologia muito mais aliada aos problemas e necessidades mundanas do que ligada à elevação do espírito, o que pode ser percebido no interior do produto midiático objeto deste trabalho.

Pode-se perceber, verificando seus discursos, que ela concebe o mundo como um campo de batalhas entre o bem e o mal, este configurado pelo demônio e seus espíritos maus aquele representado por Deus e seus anjos. Nesta luta entre estes dois campos, é necessário defender-se continuamente, a nível individual e familiar, de inimigos que desejam a desestruturação dos indivíduos e de tudo que o cerca, levando-o a ruína, tanto no âmbito pessoal quanto social, passando pela saúde e família. Este inimigo é um espírito do mau, que pode ser ativado ou enviado por outra pessoa, como também pode ser encontrado em uma esquina, onde um feitiço é realizado, pode passar de pai para filho ou adquirido junto a rituais comumente realizados por religiões afro-descendentes.

A teologia da IURD se articula ao redor de quatro pontos fundamentais: centralidade do corpo, pois ela prega a recuperação do corpo e não o seu desprezo platônico; exorcismo de espíritos maus e libertação de suas influências negativas; cura como sinônimo de salvação e prosperidade na vida; e sucesso material (teologia da prosperidade) como comprovação da presença de Deus na vida do crente.

O sincretismo religioso é de onde a IURD toma forma, ela nasce no protestantismo, mas sua maior riqueza consiste na sistematização de várias crenças já instituídas no Brasil em 
uma nova, onde cultos e crenças são ressignificados, ou seja, ela se apropriou de elementos da Igreja Católica, de religiões afro-brasileiras como Candomblé e Umbanda, com seus deuses e entidades espirituais. Por exemplo, no Candomblé e na Umbanda há espíritos bons e maus de acordo com a concepção própria dessas religiões, na Igreja Universal, todas essas entidades e espíritos são compreendidos como os responsáveis pelo mal que atinge os homens. Este sincretismo, sua aversão a certas religiões e a forte atuação da IURD dentro dos processos midiáticos vão constituir parte de sua identidade.

A IURD, por meio de estratégias que visam sua promoção, atribui a seus produtos religiosos valores adicionais, que se diferenciam dos que são ofertados pelos concorrentes. Como resultado disso, as pessoas consomem, não um objeto em si, mas o signo que substitui esse objeto, como sugere Baudrillard.

\section{SOBRE A METODOLOGIA DE ANÁLISE: A SEMIÓTICA GREIMASIANA}

Tendo em vista ser a identidade uma construção discursiva, que, no caso do presente trabalho, se manifesta via texto televisual, lança-se mão aqui da teoria semiótica, compreendida como a metodologia apropriada para dar conta da análise pretendida.

A Semiótica, segundo Greimas, tem por objetivo a exploração do sentido, não se reduzindo à descrição da comunicação. Tendo por escopo explorar o sentido do sentido, a semiótica é definida por Greimas como uma metalinguagem em relação ao universo de sentido ao qual ela se dá como objeto de análise.

Para a análise das formas de interpelação dos fiéis, essas instituições religiosas necessitam construir discursivamente suas identidades como sujeitos da interpelação, bem como de seus públicos-alvo, os interpelados, já fiéis, ou fiéis em potencial - os telespectadores. Pensa-se que a semiótica discursiva, de inspiração greimasiana, pode dar conta da análise pretendida, uma vez que não só permite a caracterização dos sujeitos envolvidos, com suas competências e performances, como o exame das formas de manipulação empregadas no processo de interpelação desses sujeitos.

Os atos de interpelação e manipulação dos sujeitos estão previstos na teoria greimasiana, em nível narrativo, constituindo-se no percurso do destinador julgador. $\mathrm{O}$ destinador manipulador é aquele que faz fazer. Para tanto, emprega uma série de figuras de manipulação que passam pela intimidação, provocação, tentação e sedução.

O sujeito só age quando interpelado e manipulado. Para que ele aja, ele é dotado de competências positiva ou negativa. 
Em nível discursivo essas ações manipulatórias ganham forma, estruturam-se através de diferentes estratégias.

Esse é o caso dos sujeitos envolvidos no programa Ponto de Luz. A igreja precisa dotar-se de competência para poder interpelar. É por isso que ela e seus pastores são configurados como um prolongamento de Deus, capaz, portanto, de solucionar os problemas dos homens ou indicar-lhes o caminho a seguir.

Os fiéis são aqueles que já optaram por esse caminho e que, portanto, já alcançaram o êxito, já solucionaram seus problemas. Por isso eles apresentam seus depoimentos.

Os fiéis em potencial são configurados como desgraçados e sofredores - doentes, viciados, desempregados, pobres, infelizes na vida afetiva e espiritual, mas, se eles se transformarem em fiéis efetivos, estarão salvos, livres e protegidos dos males que os atormentam. Essa é a promessa.

Assim, o modo de atuação discursiva da IURD é o seguinte: é instituído, em cena um representante - bispo ou pastor - que materializa discursivamente o lugar abstrato ocupado pelo sujeito absoluto - Deus, que, então, interpela os indivíduos devidamente dotados de competência - os telespectadores - fiéis ou fiéis em potencial, aqueles que, devido aos problemas por que passam estão aptos a se tornarem fiéis.

Há ainda os fiéis ou figurantes que aparecem no texto do próprio programa, como representantes desses enunciatários e que auxiliam na qualificação e interpelação dos telespectadores.

Nas emissões analisadas, dentre as quais se selecionaram duas para fazerem parte do corpo do trabalho, desenvolve-se, no processo de interpelação, um ritual que se estrutura em diferentes etapas, contendo diferentes figuras de manipulação, com vistas a convocar os telespectadores a irem ao tempo e participarem dos rituais da IURD. Essas etapas passam, como já se referiu, pela: intimidação do sujeito, por meio de ameaças de males e castigos, ou mesmo mera constatação do seu estado de carência; provocação do sujeito, com a colocação de dúvidas sobre suas condições de superar os problemas por que passa, sem o auxílio da IURD; tentação do sujeito, com promessas de êxito e prosperidade futuras, se aderir e seguir os ensinamentos da IURD; sedução do sujeito, via exaltação de suas condições de superação dos males que o atingem.

Essas diferentes etapas de manipulação atuam sobre valores modais, como o querer e o dever, o poder e o saber fazer, com vistas a convencer os já fiéis e os fiéis em potencial a adotarem a doutrina e teologia da IURD, utilizando-se, para tanto, de diferentes estratégias 
discursivas para sua manifestação, tais como a recorrência a enunciados proverbiais, a circularidade de argumentação, entre outras.

É, neste processo de manipulação, que os sujeitos envolvidos configuram suas identidades, pois, para poder interpelar todos os sujeitos envolvidos no processo, devem ser devidamente qualificados e dotados de competência. Esse é o caso tanto dos interpelantes, destinadores manipuladores, como dos interpelados, os telespectadores, sujeitos de uma ação futura.

\subsection{Procedimentos metodológicos}

Foram gravadas, para fins de análise, dez emissões do programa Ponto de Luz, entre os meses de agosto, setembro e outubro de dois mil e oito, por um período de seis semanas consecutivas. As primeiras cinco correspondem às emissões exibidas ao longo de uma semana corrida; as restantes foram gravadas, cada uma em um dia específico, sendo: a sexta emissão na segunda-feira, da segunda semana; a sétima, na terça-feira da terceira semana; a oitava, na quarta-feira da quarta semana; a nona, na quinta-feira da quinta semana; e a décima, na sextafeira da sexta semana.

Após a coleta desse corpus representativo, essas emissões foram decupadas. É essa análise que dá conta da caracterização geral do programa, definição de sua estrutura, temáticas abordadas, figuras e estratégias de convocação e manipulação dos telespectadores, e da construção das identidades da IURD, dos fies e dos fiéis em potencial.

Selecionaram-se duas dessas análises, realizadas para fazer parte do corpo do trabalho.

\section{CARACTERÍSTICAS GERAIS DO PROGRAMA}

O programa Ponto de Luz obedece a uma serialidade de apresentação: desde 2008 é exibido, de segundas a sextas-feiras, das $13 \mathrm{~h} 30$ min às 15 horas, pela Rede Bandeirantes de Televisão, com duração de 1h30min; os cultos da Igreja são temáticos, separam-se os problemas por dias de semana e interpela-se, a cada dia um tipo específico de público, trabalhando incisivamente sobre o problema que aflige aquele segmento.

Essa estratégia também é localizável nos produtos audiovisuais que a instituição produz, visto que seus programas também são desenvolvidos sobre esses temas fundamentais da igreja, no entanto, só as temáticas de domingo, segunda e terça-feira fazem parte do programa.

Sua estrutura geral comporta a seguinte sequencia: vinheta; primeiro bloco; segundo bloco e terceiro bloco. 
No interior de cada bloco há comunicações dos apresentadores e chamadas que ele invoca entre um sub-bloco e outro.

As chamadas são montagens com realocamentos de cenas recortadas de filmes, de reportagens, dos cultos, de clipes musicais de cunho religioso e de dramatizações, sempre acrescidas de musicalidade e efeitos gráficos cromáticos.

As chamadas podem conter: depoimentos de fé; apreciações sobre o culto ou sobre algum elemento ritualístico; informações sobre alguma campanha religiosa; dramatizações com base nos problemas supostamente vivenciados pelo público alvo do programa.

A montagem, tanto dos quadros quanto das chamadas é facilitada, pois todos os cultos realizados na IURD são filmados, in locu, por aparelhagens de captura e reprodução de sons e imagens, instaladas dentro da própria igreja.

Todas as emissões possuem três blocos, com temáticas relacionadas a um dia específico de culto religioso.

O primeiro bloco (com duração aproximada de 40 minutos) explora questões pertinentes ao culto que ocorre todas as terças-feiras, com o ritual intitulado: Sessão do Descarrego.

O segundo bloco (com duração aproximada 20 minutos) explora questões trabalhadas no culto do sábado, com o ritual intitulado: Causas Impossíveis;

Já o terceiro bloco (com duração aproximada 30 minutos) se refere ao culto realizado nas segundas-feiras, com ritual intitulado: Nação dos 318 ou Congresso Empresarial.

Nas emissões, o bispo ou os pastores são as figuras discursivas mais importantes, pois ancoram todas as emissões; são eles quem conduzem e movimentam toda a emissão: chamam os quadros que vêm na sequência da emissão, ou os intervalos; tomam os depoimentos de fiéis, além de serem figuras indispensáveis na construção do significado de cada montagem apresentada. Eles são o elo entre os vários segmentos da emissão; sem eles, os links não seriam compreendidos, haveria lacunas entre um tipo de segmento e outro do texto da emissão. Além disso, eles atuam, pretensamente, por delegação, não só da IURD, como também divina. Eles são homens de Deus.

A configuração discursiva desses apresentadores é muito similar, no que concerne ao teor e ao tom empregado em suas enunciações, ao figurino com o qual se apresentam, à postura que adotam e ao comportamento que têm em cena.

A apresentação de depoentes, com histórias de vida e relatos de milagres, é outro segmento característico do programa. Aliás, este é um recurso persuasivo muito poderoso, impreterivelmente utilizado pela igreja, nas mídias e nos cultos. 
Esses depoimentos, tal como são apresentados nas emissões do programa, são coletados no interior do templo religioso, seja em meio ao culto ou após o seu término. $\mathrm{O}$ repórter, ou agente que roteiriza o depoimento pode ser o bispo ou os pastores, mas, em alguns casos, o entrevistador não é visto.

No discurso de seus agentes, repete-se uma fala comum a todos os frequentadores que se apresentam, dando a impressão, muitas vezes, de que as histórias se repetem, de que as há situações vividas de forma idêntica, em diferentes contextos, pois as lembranças são ordenadas de forma muito semelhante. A simples observação do discurso de um de seus agentes-testemunho comprova isso.

A seguir, detalha-se a ficha correspondente às etapas de descrição de cada emissão, que procura aplicar algumas categorias de análise inspiradas na teoria greimasiana, aliadas a sugestões advindas do trabalho de Barthes (1982) e Athusser (1985).

A ficha compreende:

(1) Dados de identificação da emissão;

(2) Estrutura geral da emissão;

(3) Caracterização de cada bloco: temática, estrutura, decupagem;

(4) Configuração dos atores envolvidos em cada bloco;

(5) Levantamento das figuras de manipulação empregadas

\subsection{Configuração da identidade da igreja}

A IURD se dota de competência, se qualifica para atuar como interpelante, ou seja, como destinadora manipuladora que intimida, que provoca, que tenta, que seduz. E ela faz isso por delegação, através de seus representantes eclesiásticos - bispos e pastores. São eles que, fundados em sua doutrina e ideologia, convocam diretamente os telespectadores.

A IURD é uma instituição bastante autoritária e conservadora. Estrutura-se hierarquicamente em instâncias de poder interno. Mas, ao se dirigir ao telespectador, as estratégias por ela adotadas não permitem que se perceba isso de forma clara e precisa.

Ela configura sua ação, no programa, de forma muito mais branda do que ela realmente acontece; construindo para si uma imagem bastante similar a de uma entidade assistencial: está sempre disposta a ajudar a todos, independentemente da hora ou do lugar. Dá a entender que todos podem ter acesso aos pastores, que todos têm liberdade irrestrita de se relacionarem pessoalmente com ele.

Os bispos e pastores dirigem-se ao telespectador com palavras amistosas, tais como meu amigo, minha amiga. 
O religioso coloca-se como um amigo e, sendo ele o representante da igreja, no momento em que se dirige ao telespectador, coloca a IURD nesse mesmo patamar, ou seja, como local repleto de amigos com pessoas dispostas a ajudar; como uma instituição que visa o bem daquele que se aproxima.

Em muitas passagens do programa, os próprios bispo e pastores são configurados como detentores de um poder sobrenatural: eles são aqueles que estão em linha direta com Deus, os conhecedores da verdade e da vontade divina que podem pelos fiéis interceder.

O bispo e os pastores exaltam o milagre, acentuam a importância dos depoimentos ou das encenações apresentadas, objetivando com que o telespectador tome conhecimento dos sentidos atribuídos ao fiel. São esses religiosos que validam a importância de ser fiel, ou seja, são eles que identificam, nominalmente, os valores e as características do portador do título de fiel.

Para provar que a igreja tem potencial para solucionar grandes problemas na vida de seus fiéis, alguns representantes desses milagres são eleitos pela IURD para se tornarem depoentes: eles são os portadores da boa nova, aqueles em quem a força divina atuou positivamente.

Os depoentes, com seus testemunhos, assumem uma dupla função: além de representarem os fiéis e aqueles a quem a emissão se dirige, funcionam como estratégia de conferência de credibilidade à fala do pastor. Eles comprovam o que o pastor-apresentador diz, relatam a funcionalidade dos rituais e sustentam tal assertiva empiricamente, com a apresentação de atestados de saúde, com notas de quitação de dívidas, com a presença de filhos ou maridos ao culto, etc.

Em muitos depoimentos, fica difícil perceber se o agente do milagre foi realmente o ser divino ou a instituição, pois o enfoque dos depoimentos exibidos está mais direcionado à demonstração da funcionalidade da igreja. O depoimento visa, mais do que fazer com que o telespectador se identifique com o depoente e deseje "imitá-lo", comprovar que a igreja tem papel fundamental na concessão dos milagres. Ela e seus rituais são colocados como os agentes do milagre.

Outro aspecto referente à identidade iurdiana diz respeito ao modo como o fiel deve compreender o mundo que o rodeia. O mundo está repleto de desgraças, injustiças e sempre há alguém que deseja fazer mal aos outros, que invoca esses males ou age com a finalidade de prejudicar. A igreja apresenta-se como a única forma de proteção para aqueles que desejam se livrar dos males que os afligem. 
Percebe-se que os pastores se utilizam de termos que favorecem a ideia de que a igreja possui poderes que a tornam competente para auxiliar e resolver os problemas de seus fiéis.

Assim, no decorrer da emissão, são atualizados os três pilares da ideologia da Universal: as promessas de salvação, de cura e de prosperidade. Esses três pilares são constitutivos da configuração religiosa e identidade da IURD.

\subsection{Configuração da identidade dos fiéis}

A configuração mais explícita da identidade do fiel iurdiano ocorre durante os depoimentos. No entanto, os depoimentos não podem ser compreendidos como única fonte de configuração do fiel. Daí a importância de se analisar passo a passo a construção dessa identidade, para não se incorrer em generalizações apressadas.

Vale ressaltar que os fiéis depoentes nem sempre se identificam nominalmente, como tal. Mas eles apresentam características discursivas comuns. Em primeiro lugar, fica implícito que todo depoente e todo aquele que está dentro do templo, orando ou participando dos rituais, é um fiel.

O fiel da IURD possui uma história de vida que envolve dois aspectos distintos: um antes, que se caracteriza pela frustração e derrotas e um hoje, repleto de vitórias. Sua vida, no agora, é plena de bênçãos e felicidade. O iurdiano é representado como um ser pleno, feliz no amor, liberto dos espíritos que lhe faziam mau. Ele pode se identificar como detentor de bens materiais, como carro e casa, além de possuir um negócio próprio, ou ter um bom emprego, etc. No entanto, não há apenas esse tipo de depoimento. Os depoimentos com relatos de grandes acontecimentos não se constituem na maioria, embora sejam os que recebem maior espaço dentro do programa.

Não há indícios claros da forma como são selecionados esses depoentes, mas quesitos como idade e gênero são observados. A maioria dos depoentes são mulheres e senhoras.

Pode-se supor que o principal critério para a escolha dos depoimentos a serem exibidos seja a sua força de interpelação, a carga emotiva que ele traz consigo e a potência persuasiva ou manipuladora nele contida. A cura de um câncer pode se transformar em um espetáculo midiático mais atraente do que a cura de uma dor localizada. Conquistar uma casa, carro, negócio próprio e redimir toda família na fé da IURD, tem mais força manipulatória que a conquista de um novo emprego, para quem estava há seis meses desempregado.

Todo depoimento torna-se uma forma de espetáculo à parte, um espetáculo em que o produto final é o encontro do sujeito (fiel) com seu objeto de desejo, com o seu objeto de valor, concedido mediante graça ou milagre. 
É especialmente em meio a esses discursos que se podem identificar as estratégias de manipulação apontadas por Greimas, especialmente a sedução e a tentação; a provocação e a intimidação prioritariamente acionadas pelos pastores, locuções e clipes.

Como se pode ver, todos esses elementos contribuem para configurara identidade do fiel, no programa. Mas, certamente o ponto mais importante para essa conformação do fiel ocorre durante os depoimentos, quando aquele que fala se identifica como iurdiano, relata sua vida pregressa, os males que o acometiam e, finalmente, as transformações ocorridas a partir do seu ingresso e da assunção dos valores e ideologias da IURD. Isso ocorre quando o fiel interioriza todos os preceitos da igreja, vivencia sua fé e admite as prerrogativas da IURD como verdadeiras e indispensáveis à sua vida. É desse modo que a IURD atinge um de seus objetivos maiores, a configuração do fiel ideal, a quem passa a interpelar.

\subsection{Configuração da identidade dos telespectadores}

A identidade do telespectador, enquanto interpelado, começa a ser traçada desde o início do programa, já na primeira intervenção do bispo. As informações sobre a quem se destina o programa não ficam implícitas, uma vez que elas se expressam através dos depoimentos e das figuras de manipulação empregadas.

O telespectador, interpelado pela IURD, é um sujeito carente, aquele que está passando por sérias dificuldades ou sofrimentos - problemas de saúde, financeiro, de relacionamento -, quer já faça parte da comunidade iurdiana, mas tenha se afastado do templo, quer não tenha filiação religiosa determinada, nem mesmo dentro do neopentecostalismo. Ele é configurado de forma praticamente inversa a do fiel, que é tido como um vencedor: ele é pobre, desempregado, viciado, doente e com séries problemas de relacionamento, ou seja, faz parte da maioria da população brasileira.

O programa é voltado a um público majoritariamente feminino, mais especificamente, àquelas mulheres que já constituíram família.

Ao longo do programa, percebe-se a recorrência a uma tipologia de telespectadores. Cada um dos grupos recebe uma atenção discursiva específica por parte do programa. Há aqueles que não têm religião ou que não acreditam mais em sua igreja de origem; aqueles que duvidam, a priori, da IURD; e os que não a conhecem. Todos esses estão sobre a ação de um mal espiritual, que lhes causa aflições e problemas e não os deixa ir até o templo religioso, realizar o ritual.

Vale lembrar que o telespectador que se dispõe a assistir ao programa, em princípio, já possui traços que permitem sua manipulação por parte do enunciador: ele assiste ao programa 
por encontrar nele sentidos, promessas que vão ao encontro de seus desejos e aspirações. Assim, o enunciatário identifica-se com algum aspecto do programa, seja pelas estratégias discursivas empregadas, seja pela ideologia subjacente, seja pela fragilidade que sente em si. O mais provável é que o enunciatário se reconheça no fracasso e se identifique com a promessa de vitória. Afinal, quem não passa por dificuldades em sua vida cotidiana?

\section{CONSIDERAÇÕES}

Todas as formas identitárias configuradas no interior do programa são resultado da utilização de um conjunto de estratégias manipulatórias, cuidadosamente elaboradas pela emissão, com vistas a interpelar o telespectador e criar efeitos de aproximação dele com as promessas apresentadas no programa, levando-o a firmar, assim, um contrato de fé, que, posteriormente, se materializa na consecução de seu objetivo maior: levar o telespectador ao templo.

Cada instância do processo comunicativo, representada pelos três grandes segmentos do programa, tem a sua função: o fiel é aquele que leva ao conhecimento de outras pessoas o trabalho desenvolvido pela IURD; também é ele quem mantém financeiramente a IURD, bem como o programa que está no ar, através das contribuições feitas para a igreja como forma de auxílio neste processo de evangelização e agradecimento pelas bênçãos com que foi agraciado.

A oposição simples e objetiva entre o bem e o mal obedece a uma lógica facilmente absorvida pelo fiel. Multiplicar esse discurso não é difícil, já que todos os males seriam provocados pelo demônio, cujo currículo inclui a participação em outras religiões, igrejas e rituais.

Nessas conclusões, convém salientar, não são fruto apenas da análise de duas emissões do programa, mas resultado de uma longa convivência com os programas produzidos pela IURD, convivência repleta de curiosidades e indagações, instigada constantemente pela exibição de novos programas, que obedecem ao mesmo ritual, com depoimentos cada vez mais inflamados, com discursos ora agressivos, ora irônicos, mas que tem por função reiterar conteúdos de caráter ideológico e interpelar toda uma gama de sujeitos, que representam os fiéis em potencial.

As desventuras que levam os indivíduos a busca uma solução para seus problemas através de milagres continua sendo um grande mistério; talvez não se tenha uma resposta única, exata pela, para essa questão, até mesmo porque o ser humano é o mundo que ele criou 
para si, um emaranhado de razões e emoções, de causas e consequências que fazem esse mundo ser uma imensa teia de significações, de sentidos nunca capturados em sua totalidade.

Talvez quem vai buscar o milagre o encontre de fato; talvez esse milagre seja apenas uma válvula de escape encontrada por quem o procura. Pode ser ainda que esse problema seja apenas uma criação de quem o afirmam que só necessite de algumas palavras para atenuá-lo e ser plenamente feliz. Para os mais céticos, pode ser que todo esse sistema criado ao redor de milagres seja uma grande armadilha, uma encenação do início ao fim, a forma que alguns encontraram para conseguir prestígio e lucrar com a fé de outros.

Mas os tempos atuais são céleres; a instantaneidade e a urgência são valores cada vez mais presentes na sociedade. Ora, não se pode negar, o discurso iurdiano é bastante sedutor; afinal, todos já passaram por momentos de aflição e medo diante dos acontecimentos da vida. Como resistir a tentação de adotar uma solução tão fácil, rápida, milagrosa, e ao alcance de todos?

\section{REFERÊNCIAS}

ALTHUSSER, Louis. Aparelhos ideológicos de Estado: nota sobre os aparelhos ideológicos de Estado. Rio de Janeiro: Graal, 1985.

BARROS, Diana Luz Pessoa de. Teoria do discurso: fundamentos semióticos. São Paulo: Atual, 1988.

BARROS, Diana Luz Pessoa de. Teoria semiótica do texto. São Paulo: Ática, 2008.

BARTHES, Roland. Mitologias. São Paulo: Difel, 1982.

BAUDRILLARD, J. O sistema de objetos. São Paulo: Perspectiva, 1973, p. 207.

BAUMAN, Zygmunt. Modernidade líquida. Rio de Janeiro: Zahar, 2001.

BOURDIEU, P. A economia das trocas lingüísticas. São Paulo; Ática, 1983.

BROWN, J. A. C. Técnicas de persuasão: da propaganda à lavagem cerebral. 3 ed. Rio de Janeiro: Zahar, 1976.

CAMPOS. L. Silveira. A Igreja Universal do Reino de Deus: um empreendimento religioso atual e seus modos de expansão (Brasil, África e Europa). Lusotopie, 1999.

CHARAUDEAU, P. Discurso das mídias. São Paulo: Contexto, 2006.

COURTÉS, J. Introdução à semiótica narrativa e discursiva. Coimbra: Almedina, 1979. 
DEBRAY, R. . Curso de midiologia geral. Petrópolis: Vozes, 1991.

DUARTE, Elizabeth Bastos. Televisão: ensaios metodológicos. Porto Alegre: Sulina, 2004. ESTEVES, João. A ética da comunicação e os media modernos: legitimidade e poder nas sociedades complexas. Lisboa: Gulbenkian, 1998.

FABBRI, Paolo. El giro semiótico. Barcelona: Gedisa, 1999.

FOUCAULT, Michel. A ordem do discurso. São Paulo: Loyola, 1996.

FRESTON, P. Breve história do pentecostalismo brasileiro. In: ANTONIAZZI, A, ed. Nem anjos nem demônios: interpretações sociológicas do pentecostalismo. Petrópolis: Vozes, 1994.

GIDDENS, Anthony. As conseqüências da modernidade. 3. ed. São Paulo: Unesp, 1991.

GREIMAS, A. J. A propósito do jogo. Revista Verso \& Reverso, São Leopoldo, 1998.

GREIMAS, A. J. Sobre o sentido: ensaios semióticos. Petrópolis: Vozes, 1975.

GREIMAS, A. J.; COURTÉS, J. Dicionário de semiótica. São Paulo: Cultrix, 1979.

JOST, François. Seis lições sobre a televisão. Porto Alegre: Sulina: 2007.

MACEDO, Edir. Vida com abundância. 12 ed. Rio de Janeiro: Gráfica Universal, 1993.

MAFFESOLI, Michel. La conquête du présent: pour une sociologie de la vie quotidienne. Paris : Desclée de Brouwer, 1998.

MAFFESOLI, Michel. O tempo das tribos: o declínio do individualismo nas sociedades de massa. Rio de Janeiro: Forense, 1987.

MANSUR, Alexandre; VICÁRIA, Luciana. O exorcismo é a atração da noite. Revista Época, ed.258, abr.2003. Disponível em http://revistaepoca.globo.com/epoca/0, 6993, EPT527719-1664-1,00. html. Acesso em 24 ago. 2009.

PERUZZOLO, Adair Caetano. A estratégia dos signos: quando aprender é fazer. Santa Maria: UFSM. 2002.

SARLO, Beatriz. Cenas da vida pós-moderna: intelectuais, arte e videocultura na Argentina. Rio de Janeiro: UFRJ, 2000.

SODRÉ, Muniz. Antropológica do espelho: uma teoria da comunicação linear e em rede. Petrópolis: Vozes, 2002.

THOMPSON, John B. A mídia e a modernidade. Petrópolis:Vozes, 1998. 
THOMPSON, John B. Ideologia e cultura moderna: teoria social crítica na era dos meios de comunicação de massa. Petrópolis: Vozes, 1999.

TRIGUEIRO, Osvaldo Meira. A espetacularização das culturas populares ou produtos culturais folkmidiáticos. Disponível em: adewww.bocc.ubi.pt. acessado em 12 de setembro de 2008, às 18:00 horas.

Original recebido em: 30/08/2013

Aceito para publicação em: Novembro de 2013

Jozéli da Rosa Mônego

Mestre em Comunicação Social, pelo Programa de Pós-Graduação em Comunicação, da Universidade Federal de Santa Maria (2010); Bacharel em Comunicação, pelo Curso de Comunicação Social - Hab. Relações Públicas, da Universidade Federal de Santa Maria (2008); Bacharel em Ciências Sociais, pelo Curso de Ciências Sociais, da Universidade Federal de Santa Maria (2010).

\section{Elizabeth Bastos Duarte}

Graduada em Letras pela Universidade Federal do Rio Grande do Sul (1968), mestre em Letras pela Universidade Federal do Rio Grande do Sul (1982) e doutora em Lingüística e Semiótica pela Universidade de São Paulo (1989). Pós-doutora em Televisão pela École des Hautes Études en Sciences Sociales (França) e pela Université de Paris III Sorbonne Nouvelle (França). 